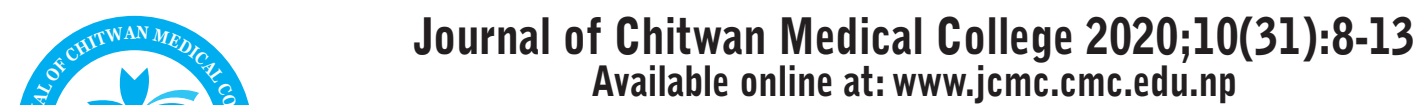

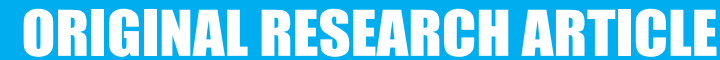

\section{CONSUMPTION OF SMOKELESS TOBACCO AND ARECA NUT AMONG ADOLESCENTS OF BHAKTAPUR, NEPAL}

Ujjwal Joshi ${ }^{1^{*}}$, Megha Pradhan ${ }^{2}$, Sirjana Dahal ${ }^{3}$, Krishan Kumar Tyagi ${ }^{4}$

${ }^{1}$ Department of Oral Medicine and Radiology, Kathmandu Medical College and Teaching Hospital, Sinamangal, Kathmandu, Nepal ${ }^{2}$ Department of Pedodontics and Preventive Dentistry, Kathmandu Medical College and Teaching Hospital, Sinamangal, Kathmandu, Nepal ${ }^{3}$ Department of Community Dentistry, Kathmandu Medical College and Teaching Hospital, Sinamangal, Kathmandu, Nepal ${ }^{4}$ Department of Oral Pathology, Kathmandu Medical College and Teaching Hospital, Sinamangal, Kathmandu, Nepal

Received: 1 Mar, 2019
Accepted: 8 Mar, 2020
Published: 13 Mar, 2020
Key words: Adolescents; Arecanut; Oral submucous
fibrosis; Smokeless tobacco.
*Correspondence to: Ujjwal Joshi, Department of Oral
Medicine and Radiology, Kathmandu Medical College
and Teaching Hospital, Sinamangal, Kathmandu, Nepal.
$\quad$ Email: drujjwaljoshi@gmail.com
DOI:https://doi.org/10.3126/jcmc.v10i1.28061
Citation
Joshi U, Pradhan M, Dahal S, Tyagi KK. Consumption of
smokeless tobacco and areca nut among adolescents
of Bhaktapur, Nepal.Journal of Chitwan Medical Col-
lege.2020;10(31):8-13.
lege.2020;10(31):8-13.

\begin{abstract}
Background: Smokeless tobacco use is prevalent in Nepal, and various Smokeless tobacco products are widely available in the country. Areca nut chewing habit is common in Nepal especially in the Terai region adjoining India. This study was aimed to assess the Smokeless Tobacco use and betel nut chewing among adolescents of Bhaktapur and to assess their knowledge about Oral Submucous Fibrosis (OSMF).
\end{abstract}

Methods: Cross-sectional study was performed among adolescents (age group 10-18) years studying in high schools and colleges in Bhaktapur. Random sampling methods was carried out to select 400 adolescents after taking written consent for questionnaire. Descriptive statistical analysis was done using SPSS version 16.

Results: Among 400 adolescents, only 24 (6\%) admitted to using smokeless tobacco and tobacco based products. One hundred sixty-two $(40.5 \%)$ participants had experienced betel nut chewing where the most common form was betel nut alone. Sixty one $(37.8 \%)$ of them had tried at special traditional functions. OSMF was never heard before among 392 (98\%) of participants.

Conclusions: Smokeless tobacco usage was seen to be less among the participants but areca nut chewing was comparatively high. Traditional functions and predominant usage of betel nut chewing at home emphasizes the need for awareness of harmful effect of betel nut chewing in any forms to be reinforced at one's home and community. Knowledge about OSMF was seen to be scanty in the adolescents.

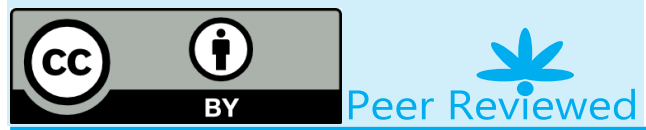

\section{INTRODUCTION}

Smokeless tobacco (SLT) use is prevalent in Nepal, and various SLT products are widely available in the country. According to the Global Youth Tobacco Survey (2011), the use of SLT was seen to be $16.2 \%$ in the youth aged $13-15$ years. ${ }^{1}$ According to the Tobacco Control and Regulation Act, use of any tobacco products are prohibited in all public places. The sale of an' form of tobacco to children under 18 years and pregnant wom en is prohibited. ${ }^{2}$

Areca nut chewing habit is common in Nepal especially in thi Terai region adjoining India. Areca nut is one of the two mail basic constituents of betel quid (wrapped areca nut, catech paste and slaked lime in a betel leaf). It is chewed in variou forms; plain supari, sweet supari, pan masala and in the forn of gutkha. Gutkha is the preparation of crushed tobacco, are ca nut, lime, catechu and flavoring agents. The independen role of areca nut in oral cancer is well documented in the lit erature. ${ }^{3-7}$ Even though various studies have been done in te rai region of Nepal, the data on the hilly areas have not bee published. The widespread selling of tobacco related product alarms the situation even in this region.
This study was aimed to assess the knowledge on consumption of smokeless tobacco and areca nut in adolescent population of Bhaktapur and to assess the level of awareness of Oral Submucous Fibrosis in same population.

\section{METHODS}

A Cross-sectional study was conducted among adolescents of age group 10-18 years after getting ethical clearance from Institutional Review Board, Kathmandu Medical College and Teaching Hospital (IRC Number: 181020197). Four schools and colleges of Bhaktapur who were ready to participate were selected with convenience sampling after taking consent from the Principle.

List of total eligible students were made and 100 students were selected by lottery method from each school from $21^{\text {st }}$ October, 2019 to $21^{\text {st }}$ February, 2020. The sample size was calculated as: $\mathrm{n}=4 \mathrm{pq} / \mathrm{I}^{2}=400$; adding $10 \%$ non-response where $\mathrm{p}$ was taken as $81.6 \%$ and $5 \%$ error. $^{8}$

Adolescent from whom assent has been taken and whose parents or guardian had given written consent for question- 
naire were included in the study while those who were under psychological medication were excluded. Independent variable taken were age, gender, and dependent variable were consumption of smokeless tobacco, areca nut, level of awareness. A standardized questionnaire was developed which was adapted from WHO surveys and the Youth Tobacco Survey, 2011. ${ }^{1}$ The original questionnaire was written in English and translated into Nepali language and changed back to English by few experts on both Nepali and English language. Pilot study was done among 40 adolescents who were not included in the main study to check if any modification was to be done in the questionnaire. Self-administered questionnaire was distributed among selected participants and collected. The doubts of the participants were clarified by the investigators during the filling of the questionnaire. The data was collected and only descriptive statistical analysis was done using SPSS version 16.

\section{RESULTS}

Among the 400 adolescents, 24 (6\%) admitted to using chewing tobacco, smokeless tobacco and tobacco-based products. Among the 24 participants, 13 (54.2\%) were between 12 to 14

years of age when they first used it (Table 1).
Table 1: Demographic details of the participants

\begin{tabular}{|l|l|}
\hline Age groups (years) & n (\%) \\
\hline $10-12$ & $45(11.2 \%)$ \\
\hline $13-15$ & $175(43.8 \%)$ \\
\hline $16-18$ & $180(45 \%)$ \\
\hline Total & $400(100 \%)$ \\
\hline Sex & $173(43.2 \%)$ \\
\hline Male & $227(56.8 \%)$ \\
\hline Female & $400(100 \%)$ \\
\hline Total & $129(32.2 \%)$ \\
\hline Grade & $135(33.8 \%)$ \\
\hline $6-8$ & $136(34.0 \%)$ \\
\hline $9-10$ & $400(100 \%)$ \\
\hline $11-12$ & \multicolumn{2}{|l}{} \\
\hline Total &
\end{tabular}

On questioned about the usage of smokeless tobacco during the past 30 days, two (29.2\%) had used for all thirty days. Seven $(29.2 \%)$ had got their own chewing tobacco, snuff or dip themselves. Nine participants $(37.5 \%)$ had bought their smokeless tobacco from a grocery store (Table 2)

Table 2: Responses of the participants who used chewing tobacco, snuff, dip

\begin{tabular}{|c|c|}
\hline How old were you when you used chewing tobacco, snuff or dip for the first time? & $\ln (\%)$ \\
\hline 1. $\quad$ Never & $0(0 \%)$ \\
\hline $2 .<-8$ & $1(4.2 \%)$ \\
\hline 3. $9-11$ & $5(20.8 \%)$ \\
\hline $4 . \quad 12-14$ & $13(54.2 \%)$ \\
\hline 5. $\quad 15-17$ & $4(16.6 \%)$ \\
\hline 6. $\quad 18-19$ & $1(4.2 \%)$ \\
\hline \multicolumn{2}{|l|}{ During the past 30 days on how many days, did you use smokeless tobacco? } \\
\hline $1 . \quad 0$ & $8(33.4 \%)$ \\
\hline 2. $1-2$ & $7(29.2 \%)$ \\
\hline 3. $3-5$ & $2(8.3 \%)$ \\
\hline 4. $6-9$ & $2(8.3 \%)$ \\
\hline 5. $\quad 10-19$ & $1(4.2 \%)$ \\
\hline 6. $20-29$ & $2(8.3 \%)$ \\
\hline 7. $\quad$ All 30 days & $2(8.3 \%)$ \\
\hline \multicolumn{2}{|l|}{ During the past 30 days, how did you get your own chewing tobacco, snuff/dip } \\
\hline 1. $\quad$ I did not use it during past 30 days & $8(33.4 \%)$ \\
\hline $2 . \quad$ I bought it myself & $7(29.2 \%)$ \\
\hline 3. I had someone else buy it for me & $0(0 \%)$ \\
\hline 4. $\quad$ I burrowed it & $1(4.2 \%)$ \\
\hline 5. $\quad$ Someone gave it to me without asking & $4(16.6 \%)$ \\
\hline 6. I took it from a store or another person & $3(12.4 \%)$ \\
\hline 7. $\quad$ I got it some other way & $1(4.2 \%)$ \\
\hline \multicolumn{2}{|l|}{ During the past 30 days, where did you buy SLT } \\
\hline 1. $\quad$ Did not buy & $12(50 \%)$ \\
\hline 2. $\quad$ Convenience store & $1(4.2 \%)$ \\
\hline 3. $\quad$ Grocery store & $9(37.5 \%)$ \\
\hline $4 . \quad$ Drug store & $0(0 \%)$ \\
\hline 5. $\quad$ Some other place not listed here & $2(8.3 \%)$ \\
\hline Total & $24(100 \%)$ \\
\hline
\end{tabular}


Table 3: Responses of the participants who did betel nut chewing

\begin{tabular}{|c|c|}
\hline If yes, Questions answered for experiencing betel nut chewing & n (\%) \\
\hline \multicolumn{2}{|l|}{ Which form of betelnut chewing have you tried? } \\
\hline 1. $\quad$ Betel nut alone & $85(52.4 \%)$ \\
\hline 2. $\quad$ Paan (betel quid) & $70(43.2 \%)$ \\
\hline Gutkha & $3(1.9 \%)$ \\
\hline 4. $\quad$ Others & $4(2.5 \%)$ \\
\hline \multicolumn{2}{|l|}{ How long have you been chewing? } \\
\hline 1. $\quad 0-12$ months & $101(62.3 \%)$ \\
\hline $1-2$ years & $33(20.4 \%)$ \\
\hline 3. $\quad>2$ to 3 years & $5(3.1 \%)$ \\
\hline 4. $\quad>3$ years & $22(13.6 \%)$ \\
\hline \multicolumn{2}{|l|}{ During the past 30 days, how many days did you use betel nut chewing } \\
\hline 1.0 & $91(56.2 \%)$ \\
\hline $1-2$ & $53(32.7 \%)$ \\
\hline $3-5$ & $4(2.5 \%)$ \\
\hline $6-9$ & $6(3.7 \%)$ \\
\hline $10-19$ & $2(1.2 \%)$ \\
\hline $20-29$ & $2(1.2 \%)$ \\
\hline 7. $\quad$ All 30 days & $4(2.5 \%)$ \\
\hline \multicolumn{2}{|l|}{ Why have you tried or experienced areca nut products? } \\
\hline 1. $\quad$ Curiosity & $27(16.7 \%)$ \\
\hline Peer pressure & $23(14.2 \%)$ \\
\hline To impress opposite sex & $2(1.2 \%)$ \\
\hline To freshen my mouth & $25(15.4 \%)$ \\
\hline Parental influence & $8(4.9 \%)$ \\
\hline Grandparents influence & $4(2.5 \%)$ \\
\hline Family/relatives influence & $2(1.2 \%)$ \\
\hline 8. $\quad$ To relieve stress & $1(0.6 \%)$ \\
\hline 9. To relieve boredom & $1(0.6 \%)$ \\
\hline 10. At special traditional functions & $61(37.8 \%)$ \\
\hline 11. Others & $8(4.9 \%)$ \\
\hline \multicolumn{2}{|l|}{ What is the preferred time for areca nut product use? } \\
\hline 1. $\quad$ After school hours & $7(4.3 \%)$ \\
\hline During play hours & $18(11.2 \%)$ \\
\hline On the way to school & $1(0.6 \%)$ \\
\hline During school hours & $4(2.5 \%)$ \\
\hline At home & $118(72.8 \%)$ \\
\hline 6. $\quad$ Others & $14(8.6 \%)$ \\
\hline \multicolumn{2}{|l|}{ How often do you chew betel nut? } \\
\hline 1. $\quad$ Once a day & $47(29 \%)$ \\
\hline Twice a day & $7(4.3 \%)$ \\
\hline Three times a day & $6(3.7 \%)$ \\
\hline$>$ three times a day & $5(3.1 \%)$ \\
\hline All day & $0(0 \%)$ \\
\hline 6. $\quad$ Once a week & $14(8.6 \%)$ \\
\hline 7. Week-ends only & $31(19.2 \%)$ \\
\hline 8. $\quad$ others & 52 (32.1\%) \\
\hline Total & $162(100 \%)$ \\
\hline
\end{tabular}


Table 4: Knowledge about Oral Submucous Fibrosis in those who have heard about it

\begin{tabular}{|c|c|}
\hline If yes, questions about oral submucous fibrosis & $\ln (\%)$ \\
\hline \multicolumn{2}{|c|}{ What do you think is the effect of oral submucous fibrosis? } \\
\hline 1. $\quad$ Normal movement of jaw & $1(12.5 \%)$ \\
\hline 2. $\quad$ Inability to open the jaw & $3(37.5 \%)$ \\
\hline 3. $\quad$ Halitosis (bad breath) & $4(50 \%)$ \\
\hline \multicolumn{2}{|c|}{ What do you think is the causative agent of this disorder? } \\
\hline 1. $\quad$ Alcohol & $3(37.5 \%)$ \\
\hline 2. $\quad$ Chewing areca nut & $0(0 \%)$ \\
\hline 3. $\quad$ Chewing betel quid & $1(12.5 \%)$ \\
\hline 4. $\quad$ Chewing areca nut and betel quid & $4(50 \%)$ \\
\hline \multicolumn{2}{|l|}{ Where do you think this disease is prevalent? } \\
\hline 1. $\quad$ South Asia & $7(87.5 \%)$ \\
\hline 2. $\quad$ USA & $0(0 \%)$ \\
\hline 3. $\quad$ Europe & $1(12.5 \%)$ \\
\hline \multicolumn{2}{|l|}{ What type of disease is OSMF? } \\
\hline 1. $\quad$ Acute lesion & $0(0 \%)$ \\
\hline 2. $\quad$ Chronic progressive lesion & $8(100 \%)$ \\
\hline \multicolumn{2}{|c|}{ Are you aware that OSMF is a potentially malignant disorder? } \\
\hline 1. $\quad$ Yes & $3(37.5 \%)$ \\
\hline $2 . \quad$ No & $2(25 \%)$ \\
\hline 3. $\quad$ Not sure & $3(37.5 \%)$ \\
\hline \multicolumn{2}{|c|}{ Do you think the treatment of OSMF will be effective after the onset of severe reduction in mouth opening? } \\
\hline 1. $\quad$ Yes & $1(12.5 \%)$ \\
\hline $2 . \quad$ No & $2(25 \%)$ \\
\hline 3. $\quad$ Not sure & $5(62.5 \%)$ \\
\hline \multicolumn{2}{|c|}{ In case of early diagnosis, what treatment do you think will be given? } \\
\hline 1. $\quad$ Abstaining from alcohol and chewing habits & $4(50 \%)$ \\
\hline 2. $\quad$ surgery & $4(50 \%)$ \\
\hline \multicolumn{2}{|c|}{ Do you think this disease could lead to the death of patient? } \\
\hline 1. $\quad$ Yes & $5(62.5 \%)$ \\
\hline 2. No & $0(0 \%)$ \\
\hline 3. $\quad$ Not sure & $3(37.5 \%)$ \\
\hline \multicolumn{2}{|c|}{ Which gender in your opinion are more affected by OSMF? } \\
\hline 1. $\quad$ Male & $7(87.5 \%)$ \\
\hline 2. $\quad$ Female & $1(12.5 \%)$ \\
\hline Total & $8(100 \%)$ \\
\hline
\end{tabular}

Those who experienced betel nut chewing were 162 (40.5\%) participants. Among those who used it, the most common form of betel nut was betel nut alone 85 (52.4\%). The participants who were using for $>3$ years were 22 (13.6\%). During the past 30 days, 4 (2.5\%) had been using it for all 30 days. The most common reason for use of areca nut was at special traditional functions seen in 61 (37.8\%) of participants. Family members influence was also seen; Parents among eight (4.9\%) and grandparents among four (2.5\%). Majority of the participants preferred time for areca nut product use was at home $118(72.8 \%)$, while play hours was the time for $18(11.2 \%)$ of the participants.
Forty-seven (29.1\%) of the participants chewed once a day (Table 3). Among the 162 participants who had betel nut chewing habit, $115(71 \%)$ of them had tried to give up the habit. Majority $350(87.5 \%)$ participants did not smoke while 84 (21\%) of the participants consumed alcohol. Awareness that betel nut chewing may cause mouth cancer was seen among 253 (63.3\%) of the participants.

Oral Submucous fibrosis was never heard before among 392 (98\%) of participants. Among the eight participants who had heard about it, only three (37.5\%) thought it causes inability to open the jaw and four (50\%) thought causative agent was chewing areca nut and betel quid. Five of them (62.5\%) 
thought OSMF could lead to death of patient (Table 4).

\section{DISCUSSION}

Tobacco use has been attributed to be one of the leading causes for the growing burden of non-communicable diseases. ${ }^{9,10}$ After the Tobacco product control and regulation act 2010, Nepal has regulated strong policy which enforces smoke free health care facilities, education institutions, government facilities, restaurants, offices and public transport. Yet the proper implementation still poses a challenge to the government. ${ }^{2}$ Due to high taxation on smoking tobacco products and low taxation on smokeless tobacco (SLT) products, increasing trend might be seen towards SLT products among the consumers. ${ }^{11}$ Our study showed only $6 \%$ of the participants consuming SLT and its products which is lesser in compared to studies done by Nipun et al ${ }^{11}$ where the prevalence was seen to be $40.1 \%$. Similar lower prevalence was seen among $8 \%$ in eastern part of Nepal by Pradhan et al ${ }^{12}$, Global Youth Survey, 2011 which had $16.2 \%$ and $21.2 \%$ in western part of Nepal indicating that the distribution of tobacco consumption in Nepal varied not only across the population subgroups but geographic regions as well. SLT was found to be more prevalent in Terai areas closer to India ${ }^{13,14}$ and the lower prevalence in our study could be due to the geographic location.

Provision of unrestricted access to tobacco products in the shops especially to the adolescents including minors, and its open use in public places pose a great challenge to the implementation of the regulations of the anti-tobacco law in Nepal. ${ }^{12}$ Nine participants of this study (37.5\%) had bought their smokeless tobacco from a grocery store similar to the study done by Pradhan et al ${ }^{12}$ which also quoted shops to be the most common source. Seven (29.2\%) adolescent in the present study had bought their own chewing tobacco themselves indicating the easy access apart from the policy.

Nearly half (54.2\%) were between 12 to14 years of age when they first used smokeless tobacco products in our study which indicated the decline in initiation of SLT in the population. These findings show similarity for study ${ }^{12}$ where the mean age was $13.58(S D=2.11)$ years. It was alarming to see one of the participants starting before the age of 8 years, which might be due to the growing popularity of the smokeless products accessible and available in small attractive sachets.

Being a multicultural and multi-ethnic country, Nepal is largely seen as an ambivalent society regarding alcohol use. Eightyfour $(21 \%)$ of the adolescents in this study consumed alcohol which was less in comparison to a study ${ }^{15}$ done in Bhaktapur which showed $56 \%$ among the youth. Residing in an area where Newari culture predominates, alcohol is served routinely in traditional functions and children are exposed at their home from their early days.

Fifty participants $(12.5 \%)$ of this study did smoking which was similar to study ${ }^{12}$ where the prevalence was $16.46 \%$ for current smokers. These findings are more than as observed by
GSHS survey 2015 , which was $7.2 \%$ for tobacco users and $5 \%$ for cigarette smokers. Adolescents' habitual smoking not only becomes a gateway to all kinds of substance abuse but also causes various health problems including upper respiratory infection, immature lung development, reduced maximum vital capacity, and lung cancer. ${ }^{16}$ The adverse effects of consuming alcohol and smoking must be disseminated to the adolescent of Bhaktapur.

Betel nut is the fourth most common addictive substance in the world. ${ }^{17}$ Chewing betel quid and areca nut is considered as a part of custom and tradition in some of the communities throughout the Indian subcontinent including Nepal and Pakistan. ${ }^{18}$ About $40 \%$ of the participants in this study had tried betel nut chewing which was slightly higher than study done by Wazir et al ${ }^{8}$ which showed prevalence of $30.4 \%$ in Parsa district of Nepal. This finding might suggest that the trend of consuming betel nut might be increasing in hilly regions too. It was alarming to know that $2.8 \%$ of the participants thought it to be beneficial to health.

The most common form was supari alone 85 (52.4\%) as every household normally tend to have in Nepal. In this study, $61(37.8 \%)$ had tried them at traditional functions while only $23(14.2 \%)$ had peer pressure in contrast to findings by Wazir et $\mathrm{al}^{8}$ where prevalent reasons were taste and by Dere et al. ${ }^{19}$ where craving was followed by taste.

Though less, the parents, grandparents and relatives were quite influential in our study depicting the use of betel nut usage to be difficult to control from one's home. Majority of the participants 118 (72.8\%) preferred areca nut use at home which indicated the easy availability. Most of the participants 115 (71\%) had tried to give up the habit that was similar as seen in study by Khan et al. ${ }^{20}$

Study done at Biratnagar among OSMF patients showed its close association with the use of chewing tobacco like gutkha, pan and areca nut. ${ }^{21}$ Most of the participants 253 (63.3\%) were aware that betel nut chewing might cause mouth cancer yet 392 (98\%) had never heard of Oral Submucous Fibrosis before the study. Among those who said to have known did not have the exact information about OSMF.

Sample size could be larger and students from other districts could be included so that the attitude and knowledge could be generalized to whole population.

\section{CONCLUSION}

Smokeless tobacco usage was seen to be less among the participants but areca nut chewing was comparatively high. Traditional functions and predominant usage of betel nut chewing at home emphasizes the need for awareness of harmful effect of betel nut chewing in any forms to be reinforced at one's home and community. Knowledge about Oral Submucous Fibrosis was seen to be scanty in the adolescents. The availability of smokeless tobacco products and areca nut products in shops 
still highlights the challenge for effective implementation of anti-tobacco law.

\section{REFERENCES:}

1. Sinha D N, Bajracharya B, Khadka B B, Rinchen S, Bhattad V B, Singh P K. Smokeless tobacco use in Nepal. Indian J Cancer. 2012;49:352-6. [DOI]

2. Ministry of Health and Population, Tobacco Control and Regulation Act 2011. Kathmandu: MOHP, 2011.

3. Shah G., Chaturvedi P., Vaishampayan S. Areca nut as an emerging etiology of oral cancers in India. Ind J Med Paediatr Oncol. 2011;33:71-79. [DOI]

4. Johnson N.W., Warnakulasuriya S., Gupta P.C., Dimba E., Chindia M., Otoh E.C. Global oral health inequalities in incidence and outcomes for oral cancer: causes and solutions. Adv Dent Res.2011;23(2):237-246. [DOI]

5. Wen C.P., Tsai M.K., Chung W.S., Hsu H.L., Chang Y.C., Chan H.T. Cancer risks from betel quid chewing beyond oral cancer: a multiple-site carcinogen when acting with smoking. Cancer Causes Control. 2010;21:14271435. [DOI]

6. Chen Y.J., Liao C.T., Chen P.J., Lee L.Y., Li Y.C., Chen I.H. Downregulation of Ches1 and other novel genes in oral cancer cells chronically exposed to areca nut extract. Head Neck. 2010;33: 257-266. [DOI]

7. Pindborg JJ, Sirsat SM. Oral submucous fibrosis. Oral Surg Oral Med Oral Pathol.1966; 22(6): 764-779. [DOI]

8. Wazir SS, Arora P, Kapoor S, Jayam R, Sharma S. Prevalence of areca nut chewing habit among high school children of Parsa district of Nepal. J Oral Biol Craniofac Res. 2017 Sep-Dec;7(3):161-166. [DOI]

9. World Health Organization: Global status report on noncommunicable diseases. Geneva: World Health Organization. (2014. Available online, [DOI]).

10. Collaborators, G. B. D. T. Smoking prevalence and attributable disease burden in 195 countries and territories, 1990-2015: a systematic analysis from the Global Burden of Disease Study 2015. Lancet 389, 1885-1906 (2017). [DOI]

11. Shrestha, N., Mehata, S., Pradhan, P.M.S. et al. A nationally representa-
CONFLICT OF INTEREST: None

FINANCIAL DISCLOSURE: None

tive study on socio-demographic and geographic correlates, and trends in tobacco use in Nepal. Sci Rep 9, 2682 (2019). [DOI]

12. Pradhan PMS, Niraula SR, Ghimire A, et al. Tobacco use and associated factors among adolescent students in Dharan, Eastern Nepal: a cross-sectional questionnaire survey. BMJ Open 2013;3:e002123. [DOI]

13. Sinha, D. N., Gupta, P. C., Ray, C. \& Singh, P. K. Prevalence of smokeless tobacco use among adults in WHO South-East Asia. Indian J Cancer 2012;49: 342-346. [DOI]

14. Singh, A. \& Ladusingh, L. Prevalence and determinants of tobacco use in India: evidence from recent Global Adult Tobacco Survey data. PLoS One 9, e114073 (2014). [DOI]

15. Maharjan PL, Magar KT (2017) Prevalence of Alcohol Consumption and Factors Associated with the Alcohol Use among the Youth of Suryabinayak Municipality, Bhaktapur. J Pharma Care Health Sys 4: 168. [DOI]

16. SH Park. Smoking and adolescent health. Korean J Pediatr. 2011 Oct; 54(10): 401-404. Published online 2011 Oct 31. [DOI]

17. Gupta PC, Ray CS. Epidemiology of betel quid usage. Ann Acad Med Singapore 2004;33(4 suppl):S31-6. PMID: 15389304

18. Verma S. Areca nut (betel nut) chewing: a popular Indian cultural practice and its mucosal implications. Int J Dermatol. 2011;50:229-232. [DOI]

19. Dere K, Choudhary P, Bhaskar V, Ganesh M, Venkataraghavan K, Shah S. Prevalence and characteristics of chewing habits of areca nut, gutka and tobacco among school children of rural areas in and around Gandhinagar District, Gujarat. J Adv Oral Res. 2014;5(2):20-26. [DOI]

20. Khan MS, Bawany FI, Shah SR, Hussain M, Arshad MH, Nisar N. Comparison of knowledge, attitude and practices of betelnut users in two socio-economic areas of Karachi. J Pak Med Assoc. 2013 Oct;63(10):131925. [DOI]

21. Mantu VK, Mitra R. To study the prevalence of oral submucous fibrosis in Biratnagar, Nepal. International Journal of Current Research. 2017; 9(12):63271-63274. [DOI] 